\title{
Janine Warnod, Chez la Baronne d'Cttingen. Paris russe et avant-gardes (1913-1935)
}

\section{Elisa Borghino}

\section{(2) OpenEdition}

1 Journals

\section{Edizione digitale}

URL: http://journals.openedition.org/studifrancesi/7012

DOI: $10.4000 /$ studifrancesi.7012

ISSN: 2421-5856

\section{Editore}

Rosenberg \& Sellier

\section{Edizione cartacea}

Data di pubblicazione: 1 septembre 2010

Paginazione: 401-402

ISSN: 0039-2944

\section{Notizia bibliografica digitale}

Elisa Borghino, «Janine Warnod, Chez la Baronne d'Ettingen. Paris russe et avant-gardes (1973-1935)»,

Studi Francesi [Online], 161 (LIV | II) | 2010, online dal 30 novembre 2015, consultato il 13 janvier 2021 URL: http://journals.openedition.org/studifrancesi/7012 ; DOI: https://doi.org/10.4000/studifrancesi. 7012

Questo documento è stato generato automaticamente il 13 janvier 2021.

\section{(c) 9 (i) $\Theta$}

Studi Francesi è distribuita con Licenza Creative Commons Attribuzione - Non commerciale - Non opere derivate 4.0 Internazionale. 


\title{
Janine Warnod, Chez la Baronne d'CEttingen. Paris russe et avant-gardes (1913-1935)
}

\author{
Elisa Borghino
}

\section{NOTIZIA}

JANINE WARNOD, Chez la Baronne d'CEttingen. Paris russe et avant-gardes (1913-1935), Paris, Édition de Conti, 2008, pp. 144.

1 Giornalista e autrice di numerose monografie a carattere artistico, Jeanine Warnod classe 1921 - ripercorre le linee guida e le vicende personali di una figura tanto singolare quanto emblematica. Oggetto dello studio è Hélène d'Cttingen, al secolo Elena Francevna, meglio conosciuta nell'ambiente artistico-letterario dell'epoca come la Baronne. Roch Grey, Léonard Pieux, François Angiboult: tre pseudonimi per un unico personaggio, tre modi di vedere e sentire originali e al tempo stesso inscindibili l'uno dall'altro. Attraverso le pagine di J. Warnod, Hélène assume via via i tratti della romanziera, della poetessa e della pittrice, fino a diventare, insieme a Serge Férat, vero e proprio mecenate delle Soirées de Paris con l'appellativo comune di Jean Cérusse, intrinseco richiamo alle origini russe dei due.

2 Il ritratto che ne emerge è quello di una donna versatile, che ha saputo esprimersi nei campi più disparati e secondo modalità sempre nuove, fino a diventare una tra le figure di spicco dell'avanguardia parigina. Il lettore riscopre così il quartiere di Montparnasse, culturalmente attivo, animarsi nei salotti di Hélène: da Archipenko a Zadkine, da Survage a Braque passando per Henri Rousseau e Max Jacob, pare non esservi artista che non si sia recato al 229 di boulevard Raspail.

3 La Baronne incanta i suoi ospiti e non solo: anche Warnod pare cedere al fascino dell'artista, e nello scegliere la chiave biografica dona alla vicenda le sembianze di un racconto, tanto che talora realtà e finzione paiono fondersi e confondersi, superando 
più volte il confine che le divide in un andirivieni costante. Ne risulta così un quadro poco oggettivo e molto impressionistico, fortunatamente accompagnato dalla galleria di illustrazioni che ancorano il testo alla realtà dei tempi.

4 Tra i vari temi affrontati, due paiono essere gli aspetti ai quali viene dato maggiore risalto: se da un lato emergono la fervida vivacità intellettuale della Baronne e la fitta rete di amicizie intessute, dall'altro viene posto l'accento sulla profonda solitudine e sulla malattia dell'artista, con sfumature forse eccessivamente accorate e talvolta tendenti al tragico. Un'impronta biografica che pare in parte intaccare la qualità della monografia - profondamente incentrata sulla vicenda intima e privata dell'artista - che vanta comunque un prezioso apparato fotografico e una ricca bibliografia, seppure non esaustiva. Notevoli anche gli scritti inediti di Roch Grey e di Léonard Pieux che corredano il volume in appendice. Molti restano tuttavia gli aspetti ancora da approfondire di un personaggio tanto enigmatico quanto controverso. 